\title{
Effects of Parent Training Programs on Parental Stress in a General Swedish Population Sample
}

\author{
Hans 0. Löfgren 1*, Solveig Petersen1,2, Karin Nilsson', Mojgan Padyab ${ }^{3}$, Mehdi Ghazinour4, \\ Bruno Hägglöf ${ }^{1}$ \\ ${ }^{1}$ Child and Adolescent Psychiatry, Department of Clinical Sciences, Umeå University, Umeå, Sweden \\ ${ }^{2}$ Epidemiology and Global Health, Department of Public Health, Umeå University, Umeå, Sweden \\ ${ }^{3}$ Department of Social Work, Umeå University, Umeå, Sweden \\ ${ }^{4}$ Police Academy, Umeå University, Umeå, Sweden \\ Email: *hans.lofgren@umu.se
}

How to cite this paper: Löfgren, H. O., Petersen, S., Nilsson, K., Padyab, M., Ghazinour, M., \& Hägglöf, B. (2017). Effects of Parent Training Programs on Parental Stress in a General Swedish Population Sample. Psychology, 8, 700-716.

https://doi.org/10.4236/psych.2017.85045

Received: December 28, 2016

Accepted: March 28, 2017

Published: March 31, 2017

Copyright () 2017 by authors and Scientific Research Publishing Inc. This work is licensed under the Creative Commons Attribution International License (CC BY 4.0).

http://creativecommons.org/licenses/by/4.0/

\begin{abstract}
This is a confirmatory study that assessed the effects of parent training programs on parental stress in a general population. There is a need to repeat and confirm earlier findings to acquire solid knowledge for policy stakeholders. In a quasi-experimental design, self-reported data were gathered at three occasions from 83 parents of children between the ages from one to ten years. These parents had responded to advertisements of parent training programs, and were matched to a comparison group of 83 parents chosen from a governmental database. Parent training program based upon behavioral, cognitive-behavioral, Adlerian and family system-theories. Parental stress due to incompetence, role restriction, social isolation, spousal relationship problems, and health problems were measured by the Swedish Parenthood Stress Questionnaire that is based on the Parent Stress Index Scale. The data indicated a reduction of stress in the sub-scale of health problems among parents in the intervention group with an effect size of 0.33 , however, no other subscale showed the intervention as a significant variable when controlling for confounding variables. This study adds on the accumulated knowledge of supporting interventions for parents. We conclude that parent training programs have a significant effect on the stress components of parental health when implemented in real-life settings.
\end{abstract}

\section{Keywords}

Parental Training Program, Parental Stress, Universal Prevention, SPSQ 


\section{Introduction}

There is a general consensus that stress is conceptualized as a discrepancy between a person's resources and the actual demands of the personal role. Psychological stress is not solely a result of environmental factors, nor is it a mere result of personality characteristics, but depends on a particular kind of person-environment relationship (Lazarus, 2006). Parental stress theory suggests that levels of parental stress are associated with a "balancing act between the parent's perceptions of the demands of this role, the child's unique personality and access to available resources for meeting these demands" (Deater-Deckard, 1998). The demands of the parent's role include perceptions of their children's behavior and their own competence (Mash \& Johnston, 1983). The children's demands also include a need for survival and thriving and unique psychological demands for attention, affection and help in regulating emotions. The resources are also diverse, sufficient income, housing, health, knowledge and support from others (Deater-Deckard, 2004). With increased parental stress come a host of planned and reactive parenting behaviors and practices that are harsher towards their children and less consistent, compared to the parenting seen in families with less parental stress (Deater-Deckard, 2004). All parents experience stress to some extent, and the daily hassles. Subsequent research support daily hassles as a significant part in the stress context for families and child development (Crnic, Gaze, \& Hoffman, 2005). Hassles are conceptualized as the irritating, frustrating, annoying, and distressing demands that to some degree characterize everyday interactions with the environment (Crnic \& Greenberg, 1990). Furthermore, the link between high levels of parental stress and negative parental behavior is well established in literature (Morgan, Robinson, \& Aldridge, 2002; Östberg \& Hagekull, 2013). Early onset and long duration of parental stress is of particular importance because it correlates with child behavior, and the responses to various sorts of stress disrupt the interaction between the parent and child (Jiménez, Mata, León, \& Muñoz, 2013; Schor et al., 2003). Finding ways to maintain parent-child communication and closeness might protect parents and families from increased stress during this vulnerable time (Prinzie et al., 2012). Previous studies have also indicated that prenatal maternal stress might lower children's cognitive abilities (Zhu et al., 2014).

Family-based interventions have been shown to benefit parents who experience high levels of stress and low levels of social support (Prado et al., 2012). Parent Training Programs (PTPs) have also been reported to strengthen parental psychosocial well-being and skills and thereby reduce stress and the use or need for medical and social services by these families (Barlow, Smailagic, Huband, Roloff, \& Bennett, 2014; Kendall, Bloomfield, Appleton, \& Kitaoka, 2013; Lindsay \& Strand, 2013). Likewise, Australian communities that implement PTPs have demonstrated a reduction in the prevalence of parental depression, stress, and coercive parenting (Sanders et al., 2008). These effects might be explained by PTPs enhancing parental capacity by discussing parental attitudes and practices in a non-judgmental and supportive way, and also by providing strategies that 
improve parental psychosocial functioning (Barlow et al., 2014). However, most studies of PTPs have been performed in populations where the child suffers from behavioral problems or where the parents have some kind of impairment (Furlong et al., 2012). Only a few general population studies of PTP outcomes are available, and they have been brief PTP's (four hours) (Hiscock et al., 2008), or the study focused on the characteristics of participants (Alfredsson \& Broberg, 2016). Few such studies have addressed the effect of these universal programs on parental stress levels (Chu, Bullen, Farruggia, Dittman, \& Sanders, 2015; Ulfsdotter, Enebrink, \& Lindberg, 2014; Zubrick et al., 2005).

The main purpose of the current study was to determine the effects of PTPs on parental stress in a general population sample. We hypothesized that parents who participated in a PTP would have a significant decrease in parental stress.

\section{Method}

\subsection{Procedures}

Parents from the general population in a larger municipality in northern Sweden were invited through advertisements in local newspapers and through flyers, information at meetings about parenting, and during personal visits to schools and kindergartens. The PTPs were offered on a web site where the parents could register and choose between four different PTPs. The parents were invited to fill in a web-based questionnaire focusing on parental stress, distributed by electronic tablets at the beginning of the first PTP meeting -T1, at the end of the last meeting -T2, and by e-mail six months post-intervention -T3. Parents who could not use the web-based questionnaire filled out a paper-and-pencil form. Parents were asked to focus on one of their children, the one they were most concerned about, when answering the questions, hereafter called focus child. Data collection from the intervention group started in April 2010, peaked in February 2012 and ended in December 2013.

A comparison group was randomly selected from a Swedish government data base (SPAR, 2010); this group was chosen to have the same distribution of children's age and urban pattern as the intervention group. The comparison group filled in an identical paper version of the questionnaire at home three times during the same timespan as the intervention group. Data collections from the comparison group took place between June and December 2013.

\subsection{Participants and Dropouts}

There were 443 parents from northern Sweden (Figure 1) who signed up for the intervention. Of these, 129 did not participate in the study, 97 dropped out after T1, and 119 dropped out between T2 and T3. Additionally, 15 parents were excluded between T1 and T2 because another child was in focus at T2; the parent was unreachable due to technical problems, or because of literacy difficulties. The final intervention group consisted of 83 participants who attended the study at all measurement points. 


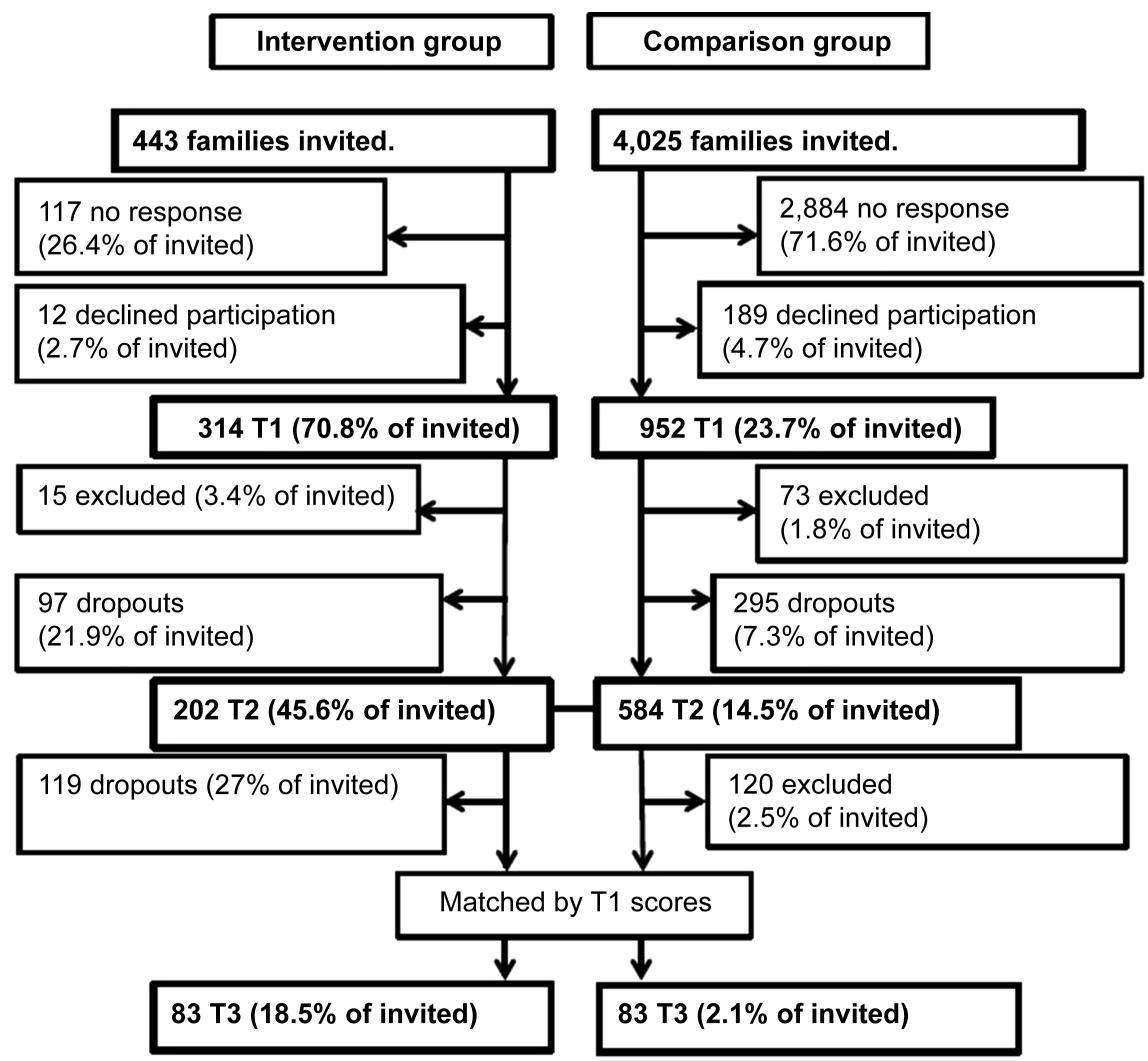

Figure 1. Flowchart of participation for intervention and comparison group.

In the comparison group, 952 of the 4025 invited families agreed to participate at T1. Of these, 584 answered the questionnaire at T2, and 464 answered the questionnaire at T3 (Figure 1). Apart from participation in the same kind of PTP as we investigated, the reasons for exclusions were the same as in the intervention group. From the 464 comparison families participating at all three occasions, 83 participants were selected by matching their total stress $\mathrm{T} 1$ score to the total stress $\mathrm{T} 1$ score of the intervention group.

\subsection{Ethical Considerations}

The Regional Ethical Review Board in Umeå approved the study with reference number 2010/249-310̈, and the study followed the APA Ethics Code. The research team offered psychosocial counselling in the information letter, and this service was provided to one parent in the intervention group. The current study is part of the comprehensive study on parental competences.

\subsection{Interventions}

The interventions included four PTPs, and the common feature of all four was that they had at least four parents gathered for at least 20 hours together with a trained leader to discuss parenting matters. The PTPs were mostly delivered on a weekly basis during the evenings. PTPs are underpinned by a range of theoretical approaches, including behavioral, cognitive-behavioural, family systems and Adlerian theories, and they involve the use of a range of delivery techniques, in- 
cluding discussions, role playing, watching video vignettes and home exercises (Kazdin, 1997). They typically involve the use of standardized curricula and themes, and they all seek to increase the knowledge, skills, and understanding of parenting. The themes of the PTPs include positive support, problem solving, disciplining, parental involvement, risk factors, and monitoring. The children's mental and physical development was also often discussed.

Active Parenting (AP) was the first manual-based interactivity program with videotapes to be introduced in Sweden. This program is delivered in three versions: "Active toddler's parents" (for parents of children younger than 2 years), "AP Today" (for parents of children between 2 - 12 years), and "AP for parents of teen" (for parents of children older than 12 years) (Birgersson-Stagling, 2013), the last one was excluded from current study. The program focuses on parents who are hesitant or uncertain in their parenting role. AP was developed by Michael Popkin and is based on Adler's theories of development and learning (Popkin, 2014). The aim of AP is to help parents take leadership in the family, and it gives them tools to handle everyday problems in a way that allows for children's independent development and good mental health.

The Community Parent Education Program (COPE) is a manual-based education program with videotapes and small group ("fishbowls") problem-solving discussions, where the conclusions of the group are captured by the PTP leader who summarizes the discussions. In Sweden, four versions of COPE are provided: "Toddlers life" (for parents of children between 2 - 3 years), "COPE" (for parents of children between 3 - 12 years), "Teenager COPE" (for parents of children older than 12 years), and "COPE for immigrant background". The last two of these were excluded from the current study. COPE was developed by Charles Cunningham and colleagues at McMaster University, and the program is based on social learning theory, social cognitive psychology, and family system theory (COPE, 2014). The aim is to give parents the means to understand and handle the behavior of their child and to enhance their parenting skills. COPE has been shown to be an effective PTP for reducing behavioral problems, hyperactivity, impulsiveness, parental stress, and daily problems, but not peer-problems, social skill deficits, or inattention (Thorell, 2009).

Family Workshop was developed by the Centre of Prevention for Stockholm City and is a manual-based communication program with written material and videotapes that targets parents of children between 3 and 12 years of age. The program comprises eight video vignettes that illustrate everyday situations and conflicts in family life. Some themes in the vignettes include spending time together, routines, positive communication, limits, and equality. Every vignette is supposed to be the basis for open discussions without pre-made questions, and the discussions are less guided than in other PTPs. Family workshop is mainly distributed by community educational associations (Bremberg, 2004).

Family-Lab was developed by Jesper Juul and consists of lectures and discussions. The program is based on Kempler's gestalt family theory (Kempler, 1974) and Juul's own experiences as a family therapist in Scandinavian countries (Schill, 
2013). The program is dominated by dialogs that seek to enhance the relationship between the responsible parent and the competent child, and it includes behavioral changes in the parent.

\subsection{Measures}

SPSQ-Swedish Parenthood Stress Questionnaire. A Swedish instrument based on parts of the Parent Domain in the Parenting Stress Index was used as a measure of stress (Östberg \& Hagekull, 2000). The SPSQ measures parents' perceptions of stress in their parenting role using a total stress scale and the five subscales of incompetence, role restriction, social isolation, spousal relationship problems, and health problems. The SPSQ contains 34 items that are scored on 5-point Likert-type scales from "not at all true" to "very true". One third of the items are positively formulated, as in "I enjoy being a parent". These items are reversed, and both subscales and total stress scales are then mean-scored. A higher score indicates higher parental stress. An earlier study confirmed the validity of the scales in a Swedish context (Lagerberg, Magnusson, \& Sundelin, 2011). In the current study, we calculated Cronbach's alpha to be 0.85 for the total stress scale.

Socio-demographics: Family variables were sex of the parent and child and marital status (dichotomized into married/common-law partner vs. single parents). The demographic questions also included the ages of the fathers, mothers, and children. Socio-economic variables included parents' and spouse education (dichotomized into less than vs. more than 12 years of education) origins of birth of the parent, spouse, and child were dichotomized into born in Sweden vs. born outside of Sweden. Working time was dichotomized into full time work vs. not full time work.

At T1, questions about parenting and the focus child were included, i.e. if the parents had experienced more worries than what could be considered normal concerning the child and if they thought the child had physical or psychological problems. The answers were categorized as no; yes, but not so much that we sought help; yes, we have sought, but not yet received, help; yes, we have received help. At T3, there was a question about the occurrences of major events that might have had greater impact on the family than the PTP, e.g. sickness, money gain or loss, or death, and the answer options were "yes" or "no".

\subsection{Statistical Analysis}

The two-tailed significance level was 0.05 . The missing values were replaced by the estimation maximization method (Little \& Rubin, 1989) if the respondents had fewer than half of the items missing in a subscale. If a parent had more than half of the items missing, the scores were reported as missing in the respective subscale. The iterations were set to 25 , and all variables in the actual subscale were used to calculate the missing value. There was a mean of $0.36 \%$ internal missing values in the questionnaire items. The respective ages of the father, mother and child co-varied and the dimension of age was reduced into one fac- 
torial variable by factor analysis (age-factor). The outcome variables for the t-tests were the difference between the T2 minus $\mathrm{T} 1$ scores and the T3 minus $\mathrm{T} 1$ scores. The preliminary analysis included Levene's test for equal variance in subgroups. The differences for all variables between the intervention group and the dropouts and between the intervention group and the comparison group were analyzed with t-tests for continuous variables and Pearson's chi-square test for ordinal data. At T1, the correlations between the variables were tested with the Pearson correlation coefficient for continuous variables and with Kendall's Tau correlation for ordinal and nominal data. Pair-wise and independent t-tests were conducted for the total stress scale and all of the subscales to generate the preliminary results. Effect sizes were calculated in the t-test according to Cohen's $\mathrm{d}$-value, with values of 0.2 defined as a small effect size; 0.5 as a medium effect size; and 0.8 as a large effect size. In analysis of variances (ANOVA) according to partial eta square $\left(\mathrm{p} . \eta^{2}\right)$, values of 0.02 to 0.12 were defined as a small effect size, 0.13 to 0.25 as a medium effect size, and over 0.26 as a large effect size (Cohen, 1988). The relative importance of predictors was calculated by Pratt's measure (Pratt, 1987). Pratt's measure uses relative importance as the predictor of different variables' contributions to the regression. These measures are computed by taking the product of each regression coefficient and their simple correlations and comparing them to the sum of the product of the regression coefficients and their simple correlations. Large individual importance, relative to the other variables, corresponds to predictors that are crucial to the regression.

Repeated measure by stepwise backward elimination ANOVA was done to analyze the intervention effect looked at the within-subjects differences at the three measuring points, and the most important variables gathered from the Pratt's measure were the between-subject variables. The questionnaire data was analyzed using IBM SPSS, version 21.0.0.1 (International Business Machines Corporation, 2015).

\section{Results}

\subsection{Group Differences}

The intervention group and comparison group were similar with regard to marital status, sex of the respondents, parental education, employment, and migrant status, as well as with regard to the child's sex and migrant status (Table $1)$.

However, both fathers and mothers in the intervention group were somewhat younger than fathers and mothers in the comparison group, while the focus child was older in the intervention group than in the comparison group. In addition, family size differed between the two groups with more single-child families in the comparison group. Finally, the intervention group reported more worries for the child and more psychological problems for the child, but fewer physical problems for the child, than the comparison group.

The significant difference between the intervention group and the dropout group at T2 was that the intervention group had more higher-educated parents 
Table 1. Demographic and problem variables.

\begin{tabular}{|c|c|c|c|c|}
\hline \multirow{4}{*}{ Baseline variable } & & \multirow{3}{*}{ Intervention } & \multirow{3}{*}{ Comparison } & \multirow{2}{*}{$\begin{array}{c}\text { Parents in } \\
\text { Sweden } 2011\end{array}$} \\
\hline & & & & \\
\hline & & & & (20 - 55 years old) \\
\hline & & group $(\mathrm{n}=83)$ & group $(n=83)$ & $(\mathrm{n}=4,709,057)$ \\
\hline \multicolumn{5}{|l|}{ Parent/family characteristics } \\
\hline Age of the father M (SD) & 20 to 55 years & $35.62(5.19)^{*}$ & $37.58(5.73)^{\star}$ & $35.27^{\mathfrak{v}} \bullet$ \\
\hline Age of the mother M (SD) & 20 to 48 years & $33.43(4.99)^{*}$ & $35.54(5.17)^{\star}$ & $32.93^{\mathrm{D}} \bullet$ \\
\hline Marital status n (\%) & Married/partner & $69(87.3)$ & $79(95.2)$ & $4,372,512(92.9)$ \\
\hline Sex of the respondent $\mathrm{n}(\%)$ & Female & $74(89.2)$ & $76(91.6)$ & $2,443,631(51.9)$ \\
\hline Family size n (\%) & One-child families & $9(10.8)^{*}$ & $27(32.5)^{*}$ & $448,076(38.1)$ \\
\hline Father's education $\mathrm{n}(\%) \diamond$ & $>12$ years & $43(61.4)$ & $48(62.3)$ & $743,538(33.8)$ \\
\hline Mother's education $\mathrm{n}(\%) \diamond$ & $>12$ years & $59(77.6)$ & $72(87.8)$ & $929,204(43.5)$ \\
\hline Employment n (\%) & Full time work & $62(74.7)$ & $50(69.4)$ & $3,555,000(75.5)$ \\
\hline Origin of the father $\mathrm{n}(\%)$ & In Sweden & $77(95.1)$ & $74(90.2)$ & $1,902,598(84.0)$ \\
\hline Origin of the mother $\mathrm{n}(\%)$ & In Sweden & $76(93.8)$ & $78(95.1)$ & $2,217,461(83.1)$ \\
\hline \multicolumn{5}{|l|}{ Child characteristics } \\
\hline Age of the child M (SD) & 1 to 10 years & $4.22(2.01)^{*}$ & $3.51(2.35)^{*}$ & $\bullet$ \\
\hline Sex of the child n (\%) & Boy & $48(60.8)$ & $47(56.6)$ & $1,331,640(53.2)$ \\
\hline Origin of the child n (\%) & In Sweden & $71(100.0)$ & $73(98.6)$ & $2,038,778(81.4)$ \\
\hline \multicolumn{5}{|l|}{ Problem variables } \\
\hline More worries about the child than normal n (\%) & Yes & $21(25.3)^{*}$ & $9(10.8)^{*}$ & $\bullet$ \\
\hline Worries about physical problems for the child n (\%) & Yes & $6(7.4)^{*}$ & $21(25.3)^{\star}$ & $\bullet$ \\
\hline Worries about psychological problems for the child $\mathrm{n}(\%)$ & Yes & $14(17.3)^{*}$ & $5(6.0)^{*}$ & $\bullet$ \\
\hline $\begin{array}{l}\text { Did something happen that had a big impact upon your family } \\
\text { from the time you started parental training? } \mathrm{n}(\%)\end{array}$ & Yes & $14(17.3)$ & $14(18.4)$ & $\bullet$ \\
\hline
\end{tabular}

Note: Missing data are subtracted from the per cent sum. ${ }^{\star}$ Pearson chi $^{2}$ or $\mathrm{t}$-test shows a significant $(p<0.05)$ difference between the intervention and comparison group. $\diamond$ Spousal education reported. $\bullet$ No data. ${ }^{\circ}$ The mean age of the parents of the first child's birth plus the mean age of the child in the study. National data from (SCB 2011).

and more two-child families. The differences in psychological problems for the child and physical problems for the child could not be calculated due to missing data. The dropouts in the intervention group between $\mathrm{T} 2$ and $\mathrm{T} 3$ did not differ from the remaining participants in $\mathrm{T} 3$.

\subsection{Basic Hypothesis Tests}

Using Levene's test of variance, the results showed that there were un-equal variances in the intervention group and comparison group in the SPSQ subscales of incompetence at $\mathrm{T} 3$, role restriction at $\mathrm{T} 3$, and social isolation at $\mathrm{T} 3$ and in the total stress scale at T3. A paired-sample t-test was performed to explore the change between the pre-intervention and post-intervention mean measures (Table 2). 
H. O. Löfgren et al.

Table 2. Pair-wise $t$-tests of changes in parental stress compared to T1.

\begin{tabular}{|c|c|c|c|c|c|c|c|c|}
\hline \multirow[b]{2}{*}{ Scale } & \multirow[b]{2}{*}{ Group } & \multirow[b]{2}{*}{ Mean score on the SPSQ subscales } & \multicolumn{6}{|c|}{ Paired differences } \\
\hline & & & SD & Mean & SD & $t$-value & $d f$ & $p$-value \\
\hline \multirow[t]{4}{*}{ Incompetence } & Intervention $\mathrm{T} 2$ & 2.49 & 0.66 & $-0.17^{\star}$ & 0.37 & -4.05 & 71 & $<0.001$ \\
\hline & Intervention $\mathrm{T} 3$ & 2.60 & 0.58 & -0.06 & 0.50 & -1.00 & 77 & 0.32 \\
\hline & Comparison T2 & 2.37 & 0.65 & -0.07 & 0.35 & -1.72 & 80 & 0.09 \\
\hline & Comparison T3 & 2.35 & 0.64 & -0.08 & 0.45 & -1.68 & 81 & 0.10 \\
\hline \multirow[t]{4}{*}{ Role Restriction } & Intervention $\mathrm{T} 2$ & 3.41 & 0.71 & $-0.20^{*}$ & 0.56 & -3.08 & 71 & 0.003 \\
\hline & Intervention $\mathrm{T} 3$ & 3.37 & 0.83 & $-0.26^{*}$ & 0.65 & -3.47 & 74 & 0.001 \\
\hline & Comparison T2 & 3.42 & 0.64 & -0.09 & 0.48 & -1.69 & 80 & 0.10 \\
\hline & Comparison T3 & 3.43 & 0.67 & $-0.10^{*}$ & 0.43 & -1.99 & 79 & 0.05 \\
\hline \multirow[t]{4}{*}{ Social Isolation } & Intervention $\mathrm{T} 2$ & 2.07 & 0.65 & $-0.24^{\star}$ & 0.50 & -4.03 & 71 & $<0.001$ \\
\hline & Intervention $\mathrm{T} 3$ & 2.39 & 0.61 & 0.01 & 0.59 & -0.08 & 80 & 0.94 \\
\hline & Comparison T2 & 2.19 & 0.64 & -0.07 & 0.48 & -1.30 & 80 & 0.20 \\
\hline & Comparison T3 & 2.23 & 0.63 & -0.16 & 0.52 & -0.27 & 80 & 0.79 \\
\hline \multirow[t]{4}{*}{ Spousal Problems } & Intervention $\mathrm{T} 2$ & 2.27 & 0.66 & -0.08 & 0.49 & -1.41 & 67 & 0.16 \\
\hline & Intervention $\mathrm{T} 3$ & 2.37 & 0.79 & 0.01 & 0.58 & 0.21 & 73 & 0.84 \\
\hline & Comparison T2 & 2.52 & 0.82 & 0.02 & 0.65 & 0.25 & 79 & 0.80 \\
\hline & Comparison T3 & 2.51 & 0.84 & 0.02 & 0.71 & 0.28 & 79 & 0.78 \\
\hline \multirow[t]{4}{*}{ Health Problems } & Intervention $\mathrm{T} 2$ & 2.72 & 0.66 & $-0.18^{\star}$ & 0.52 & -2.89 & 71 & 0.01 \\
\hline & Intervention $\mathrm{T} 3$ & 2.70 & 0.70 & $-0.20^{\star}$ & 0.68 & -2.68 & 79 & 0.01 \\
\hline & Comparison T2 & 2.82 & 0.86 & $-0.15^{\star}$ & 0.59 & -2.27 & 80 & 0.03 \\
\hline & Comparison T3 & 3.00 & 0.78 & 0.02 & 0.72 & 0.19 & 81 & 0.85 \\
\hline \multirow[t]{4}{*}{ Total stress } & Intervention $\mathrm{T} 2$ & 2.59 & 0.45 & $-0.18^{*}$ & 0.32 & -4.61 & 67 & $<0.001$ \\
\hline & Intervention $\mathrm{T} 3$ & 2.69 & 0.50 & -0.09 & 0.40 & -1.77 & 66 & 0.08 \\
\hline & Comparison T2 & 2.63 & 0.46 & $-0.07^{\star}$ & 0.28 & -2.23 & 79 & 0.03 \\
\hline & Comparison T3 & 2.65 & 0.45 & -0.03 & 0.29 & -1.16 & 78 & 0.25 \\
\hline
\end{tabular}

Note: ${ }^{*}=$ statistical significant. Negative values in the mean paired difference indicate stress reduction. $d f=$ degree of freedom.

The t-test showed that the stress scores decreased at $\mathrm{T} 2$ for the intervention group in all subscales except spousal problems. The decrease in stress was retained at $\mathrm{T} 3$ for role restriction and health problems, but there were no changes between $\mathrm{T} 1$ and $\mathrm{T} 3$ for the subscales of incompetence, social isolation, spousal problems, or total stress scale. The comparison group had a significant decrease at $\mathrm{T} 2$ in the health problem subscale and in the total stress scale, and they had a significant decrease at $\mathrm{T} 3$ for role restrictions. The two groups showed no mean value increase over time in any subscale at any point. Independent sample t-tests showed that the intervention group had a greater decrease from $\mathrm{T} 1$ to $\mathrm{T} 2$ in the social isolation subscale and in total stress scale than the comparison group (Table 3). 
Table 3. Independent t-test between the intervention and comparison group.

\begin{tabular}{lcccccc}
\hline & \multicolumn{6}{c}{ t-test for equality of means between the groups } \\
\hline Change from T1 to: & Mean difference & Mean SD & $t$-value & $d f$ & $p$-value & $d$-value \\
\hline Incompetence T2 & -0.11 & 0.36 & -1.84 & 151 & 0.07 & \\
Incompetence T3 & 0.03 & 0.48 & 0.35 & 158 & 0.73 & \\
Role restriction T2 & -0.11 & 0.52 & -1.35 & 151 & 0.18 & \\
Role restriction T3 & -0.17 & 0.54 & -1.90 & $125.30 *$ & 0.06 & \\
Social isolation T2 & -0.17 & 0.49 & -2.13 & 151 & 0.04 & 0.35 \\
Social isolation T3 & 0.02 & 0.56 & 0.24 & 160 & 0.81 & \\
Spousal problems T2 & -0.10 & 0.50 & -1.06 & 146 & 0.29 & \\
Spousal problems T3 & -0.04 & 0.61 & -0.35 & 152 & 0.73 & \\
Health problems T2 & -0.03 & 0.52 & -0.30 & 151 & 0.76 & \\
Health problems T3 & -0.22 & 0.66 & -1.99 & 160 & 0.05 & 0.33 \\
Total stress scale T2 & -0.11 & 0.30 & -2.22 & 146 & 0.03 & 0.37 \\
Total stress scale T3 & -0.05 & 0.35 & -0.97 & $117.00^{*}$ & 0.39 & \\
\hline
\end{tabular}

${ }^{\star}$ Equal variances not assumed.

At T3, there was a significant decrease in health problems in the intervention group compared to the comparison group, as shown in Table 3, Table 4 and Figure 2. All significant differences had a small to medium effect size.

\subsection{Important Predictors}

Pratt's measure indicates that the baseline score at $\mathrm{T} 1$ proved to have the greatest impact (Table 4).

Additional important variables were age for the incompetence subscale, marital status for the role restriction subscale, education level of the fathers for the social isolation subscale, family size and sex of the child for the spousal problems subscale, education level of the father and sex of the child for the health problems subscale, and age for the total stress scale.

\subsection{Controlled Results}

Those important predictors that made the largest contribution to the regression were included in a rANOVA (Table 5) together with the interaction between the predictors and the intervention.

The result of this analysis showed that there was a significant change in the subscales of role restriction, social isolation, and health problems over time ( $p<$ $0.01)$. There were no changes in the subscales of incompetence or spousal problems or in the total stress scale. Initially the spousal problem subscale was the only one in which the intervention group had lower T1 scores than the comparison group. 
Table 4. Relative importance of predictors' contributions to the backward linear regression.

\begin{tabular}{|c|c|c|c|c|}
\hline & Adj $R^{2}$ & Coefficients & Importance & Significance \\
\hline \multirow[t]{20}{*}{$\mathrm{T} 2$} & 0.21 & Incompetence & & \\
\hline & & T1 score & $70.8 \%$ & $<0.001$ \\
\hline & & Age factor & $29.2 \%$ & 0.002 \\
\hline & 0.12 & Role restriction & & \\
\hline & & T1 score & $72.3 \%$ & $<0.001$ \\
\hline & & Single parent & $27.7 \%$ & 0.01 \\
\hline & 0.23 & Social isolation & & \\
\hline & & T1 score & $67.0 \%$ & $<0.001$ \\
\hline & & $\begin{array}{l}\text { Father's lower } \\
\text { education }\end{array}$ & $10.7 \%$ & 0.04 \\
\hline & 0.22 & Spousal problems & & \\
\hline & & T1 score & $51.9 \%$ & $<0.001$ \\
\hline & & More children & $38.6 \%$ & $<0.001$ \\
\hline & & Boy & $9.5 \%$ & 0.05 \\
\hline & 0.18 & Health problems & & \\
\hline & & T1 score & $75.6 \%$ & $<0.001$ \\
\hline & & $\begin{array}{l}\text { Fathers lower } \\
\text { education }\end{array}$ & $12.4 \%$ & 0.04 \\
\hline & & Boy & $12.0 \%$ & 0.05 \\
\hline & 0.22 & Total stress scale & & \\
\hline & & T1 score & $62.0 \%$ & $<0.001$ \\
\hline & & Older age & $19.9 \%$ & 0.02 \\
\hline \multicolumn{5}{|l|}{$\mathrm{T} 3$} \\
\hline & 0.24 & Incompetence & & \\
\hline & & T1 score & $92.4 \%$ & $<0.001$ \\
\hline & 0.03 & Role restriction & - & - \\
\hline & & Intervention & $60.4 \%$ & 0.05 \\
\hline & 0.25 & Social isolation & & \\
\hline & & T1 score & $95.7 \%$ & $<0.001$ \\
\hline & 0.18 & Spousal problems & & \\
\hline & & T1 score & $86.2 \%$ & $<0.001$ \\
\hline & & More children & $13.8 \%$ & 0.03 \\
\hline & 0.28 & Health problems & & \\
\hline & & T1 score & $83.5 \%$ & $<0.001$ \\
\hline & & Intervention & $9.2 \%$ & 0.02 \\
\hline & & More children & $7.3 \%$ & 0.03 \\
\hline & 0.16 & Total stress scale & & \\
\hline & & T1 score & 84.1 & $<0.001$ \\
\hline
\end{tabular}

Note: Only significant coefficients are shown. 


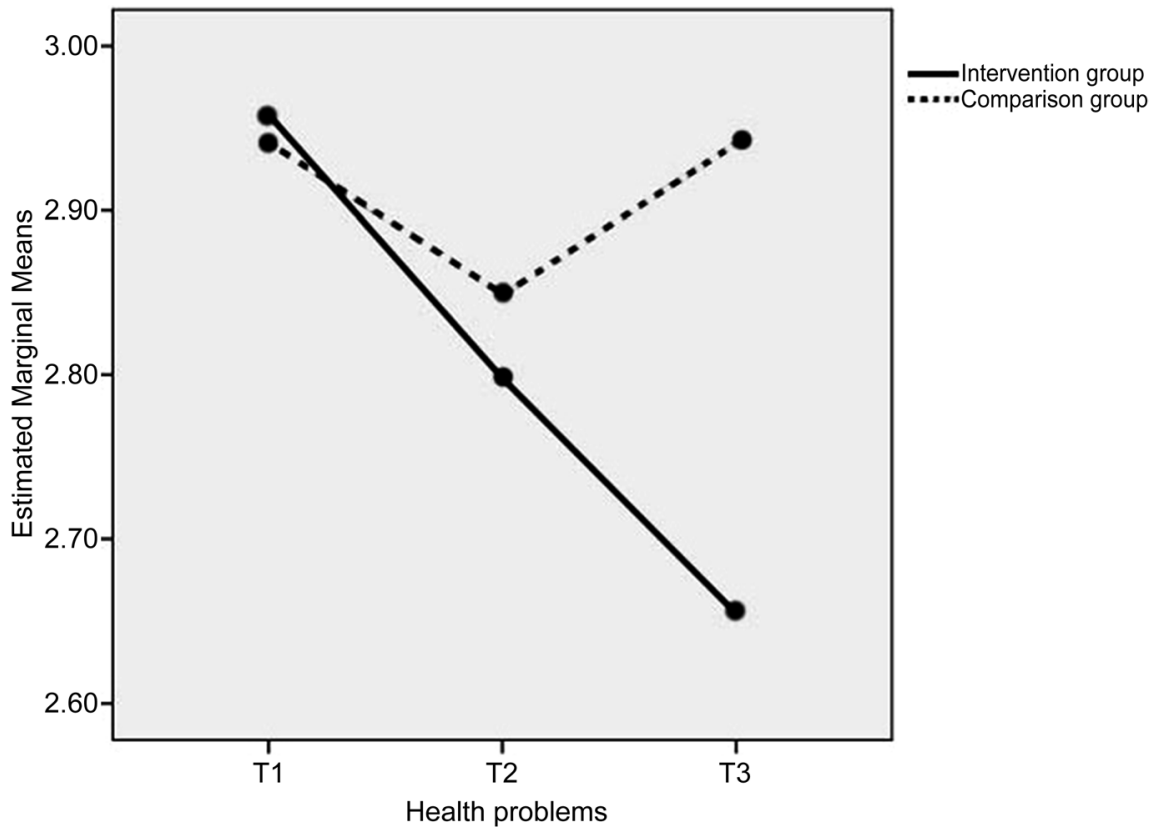

Figure 2. Repeated measures of health problems in the intervention group and Comparison group.

Table 5. Repeated measures test of within-subjects effects of the intervention.

\begin{tabular}{ccccc}
\hline Scale $\times$ intervention & $F$ & $p$ & $p . \eta^{2}$ & Power \\
\hline Incompetence $^{2}$ & 0.44 & 0.62 & n.a. & n.a. \\
Role restriction $^{1}$ & 3.57 & 0.03 & 0.03 & 0.66 \\
Social isolation $^{1}$ & 3.66 & 0.03 & 0.03 & 0.67 \\
Spousal problems $^{2}$ & 1.57 & 0.21 & n.a. & n.a. \\
Health problems $^{2}$ & 3.88 & 0.03 & 0.03 & 0.66 \\
Total stress scale $^{2}$ & 0.86 & 0.42 & n.a. & n.a. \\
\hline
\end{tabular}

${ }^{1}=$ Sphericity assumed. ${ }^{2}=$ Greenhouse-Geisser. $\mathrm{p} . \eta^{2}=$ Partial eta square $>.02$ is a medium effect size. n.a. $=$ not applicable.

The adjusted difference between the intervention group and the comparison group in the health problems subscale was particularly noticeable (Figure 2).

The intervention group had an initial mean score of 2.99 that dropped to 2.74 at T2 and kept dropping to 2.69 at T3, while the comparison group started at 2.98 and dropped to 2.78 but then returned to the initial score of 2.98 . This decrease in health problems in the intervention group was even more prominent when the child was a girl, and this led to an additional 0.05 point drop at $\mathrm{T} 3$.

\section{Discussion}

The aim of this short-term longitudinal study was to increase knowledge of the effects of PTPs on parental stress in a general population sample. The unique characteristic of this study was that it assessed four PTP's outcome in one study. The main result is that perceived health problems were significantly decreased, 
and this was foremost due to participation in a PTP more than any other predictor, while pre-intervention baseline scores on the SPSQ subscales were otherwise the dominating predictors of the other subscales of parental stress. The significant impact of the baseline scores at $\mathrm{T} 1$ implies that parents who voluntarily seek and participate in PTPs have a higher stress level than the comparison group; this was also seen in a demographic study of participants of PTP's (Alfredsson \& Broberg, 2016). By offering PTPs broadly, it is likely that those who participate will experience improved health.

The independent $\mathrm{t}$-tests between the intervention group and the comparison group showed a significant difference directly after the conclusion of the PTPs in the subscales of social isolation and health problems and for the total stress scale. After six months, this difference had faded in the social isolation subscale and the stress total scale, but it remained in the health problems subscale. The subjects of the questions about stress-related health problems were rather wide, and the questions in the subscale asked about infections, physical fitness, fatigue, and the frequency of illness. Also the age range of the children was wide to include different stages of development phases.

An explanation for this difference in health problems between the intervention group and the comparison group can be a two-stage model of stress release. Firstly there is the relief that is often felt when one understands the normal development and behavior of children (Deater-Deckard, 1998; Hiscock et al., 2008) and the normality of one's own daily parental problems (Crnic \& Greenberg, 1990), secondly there might be a new problem with focused strategies received from the PTP's theories (Bremberg, 2004; Kendall et al., 2013; Malti, Ribeaud, \& Eisner, 2011; Thorell, 2009). There is a logical path between stress release and the absence of daily or multiple incidents, and this explanation has also been suggested in those other studies. The fact that having more children in the family was a predictor of improved health (c.f. Table 4) might be the result of a synergistic effect in which siblings also react positively to new and more functional parental strategies received from the PTP's theories. However, further research on this subject is required.

There was a borderline significant effect of the intervention in the role restriction subscale $(p=0.049)$ at T3 t-tests. This borderline significant result was confirmed in the Pratt's measure $(p=0.054)$, which failed to reach significance and thus indicated that there were no other predictors. This means that the release of feeling restricted to the parenting role might be a result of chance, and no background factor seems to be relevant. It also seems that PTPs have no major influence on the relationship between spouses as measured by the SPSQ.

Contrary to our expectations, the comparison group had a significant decrease in stress in the health problems subscale and the total stress scale at T2 and a decrease in stress in the role restriction subscale at $\mathrm{T} 3$ according to the t-test. We interpret this as an effect of participating in the study as a parent in the comparison group, and being made aware of one's parental skills when answering the questionnaire might be a minor intervention in itself. 
The findings in this study are limited by the low response rate. This was also observed in other studies of universal prevention PTP's, e.g. Lindsay and Strand (2013) where the response rate was $54.1 \%$ at $\mathrm{T} 2$ and $16.8 \%$ at $\mathrm{T} 3$. This can be compared to response rates in this study of the intervention group that was $45.6 \%$ at $\mathrm{T} 2$ and $18.5 \%$ at $\mathrm{T} 3$ (Figure 1 ).

\section{Conclusion}

These findings suggest that PTPs are likely to reduce stress about health problems among parents in the general population. This effect has previously been shown in a targeted population, and this study can now add knowledge about the effect when parents themselves volunteer to participate in a PTP. The conclusion is that parents in need seek PTP for themselves if offered. The result is consistent with other studies on parental stress in a universal setting.

\section{Acknowledgements}

This study was funded by the Swedish National Institute of Public Health (grant numbers HFÅ2009/192 (NKC2009/20) and HFÅ2010/95 (NKC2010/44)). We would like to thank all of the participating parents who willingly contributed to the collected data, Lena Grundberg for assistance in data collection and Håkan Lindkvist at the Department of Mathematical Statistics at Umeå University for his valuable advice.

The materials contained in the SPSQ are partly adapted and modelled after the Parenting Stress Index, Copyright 1990 by Psychological Assessment Resources, Inc. and reproduced by permission of PAR, Inc. Unfortunately an appendix with an English version could not be added. To obtain a copy of the Swedish Parenting Stress Index, please contact PAR, Inc. at P. O. Box 998, Odessa, FL, 33556 (telephone: (813) 968-3003) or via their website at www.parinc.com.

\section{References}

Alfredsson, E. K., \& Broberg, A. G. (2016). Universal Parent Support Groups for Parents of Adolescents: Which Parents Participate and Why? Scandinavian Journal of Psychology, 57, 177-184. https://doi.org/10.1111/sjop.12278

Barlow, J., Smailagic, N., Huband, N., Roloff, V., \& Bennett, C. (2014). Group-Based Parent Training Programmes for Improving Parental Psychosocial Health. Cochrane Database of Systematic Reviews, No. 5, Article No. CD002020. https://doi.org/10.1002/14651858.CD002020.pub4

Birgersson-Stagling, A. (2013). Active Parenting, General Information Website. http://www.activeparenting.se/

Bremberg, S. (Red.) (2004). New Tools for Parents-Suggestions to New Forms of Parental Support. Sandviken.

Chu, J. T., Bullen, P., Farruggia, S. P., Dittman, C. K., \& Sanders, M. R. (2015). Parent and Adolescent Effects of a Universal Group Program for the Parenting of Adolescents. Prevention Science, 16, 609-620. https://doi.org/10.1007/s11121-014-0516-9

Cohen, J. (1988). Statistical Power Analysis for the Behavioral Sciences. New York: Psychology Press. 
COPE, Swedish COPE Association (2014). COPE-Community Parent Education Program. http://www.svenskacope.se/

Crnic, K. A., \& Greenberg, M. T. (1990). Minor Parenting Stresses with Young Children. Child Development, 61, 1628-1637. https://doi.org/10.2307/1130770

Crnic, K. A., Gaze, C., \& Hoffman, C. (2005). Cumulative Parenting Stress across the Preschool Period: Relations to Maternal Parenting and Child Behaviour at Age 5. Infant and Child Development, 14, 117-132. https://doi.org/10.1002/icd.384

Deater-Deckard, K. (1998). Parenting Stress and Child Adjustment: Some Old Hypotheses and New Questions. Clinical Psychology: Science and Practice, 5, 314-332. https://doi.org/10.1111/j.1468-2850.1998.tb00152.x

Deater-Deckard, K. (2004). Parenting Stress. New Haven, CT: Yale University Press. https://doi.org/10.12987/yale/9780300103939.001.0001

Furlong, M., McGilloway, S., Bywater, T., Hutchings, J., Smith, S. M., \& Donnelly, M. (2012). Behavioural and Cognitive-Behavioural Group-Based Parenting Programmes for Early-Onset Conduct Problems in Children Aged 3 to 12 Years. Cochrane Database of Systematic Reviews, No. 2, Article No. CD008225. https://doi.org/10.1002/14651858.CD008225.pub2

Hiscock, H., Bayer, J. K., Price, A., Ukoumunne, O. C., Rogers, S., \& Wake, M. (2008). Universal Parenting Programme to Prevent Early Childhood Behavioural Problems: Cluster Randomised Trial. BMJ, 336, 318-321. https://doi.org/10.1136/bmj.39451.609676.AE

International Business Machines Corporation (2015). http://www.ibm.com/legal/copytrade.shtml

Jiménez, J. M., Mata, E., León, E., \& Muñoz, A. (2013). Parental Stress and Children Adjustment in Kinship Foster Families. The Spanish Journal of Psychology, 16, E39. https://doi.org/10.1017/sjp.2013.41

Kazdin, A. E. (1997). Parent Management Training: Evidence, Outcomes, and Issues. Journal of the American Academy of Child \& Adolescent Psychiatry, 36, 1349-1356. https://doi.org/10.1097/00004583-199710000-00016

Kempler, W. (1974). Principles of Gestalt Family Therapy: A Gestalt-Experiential Handbook. Kempler Inst.

Kendall, S., Bloomfield, L., Appleton, J., \& Kitaoka, K. (2013). Efficacy of a Group-Based Parenting Program on Stress and Self-Efficacy among Japanese Mothers: A QuasiExperimental Study. Nursing \& Health Sciences, 15, 454-460. https://doi.org/10.1111/nhs.12054

Lagerberg, D., Magnusson, M., \& Sundelin, C. (2011). Child Health and Maternal Stress: Does Neighbourhood Status Matter? International Journal of Adolescent Medicine and Health, 23, 19-25. https://doi.org/10.1515/ijamh.2011.004

Lazarus, R. S. (2006). Stress and Emotion : A New Synthesis. New York: Springer Publishing Company.

Lindsay, G., \& Strand, S. (2013). Evaluation of the National Roll-Out of Parenting Programmes across England: The Parenting Early Intervention Programme (PEIP). BMC Public Health, 13, 972. https://doi.org/10.1186/1471-2458-13-972

Little, R. J. A., \& Rubin, D. B. (1989). The Analysis of Social Science Data with Missing Values. Sociological Methods \& Research, 18, 292-326. https://doi.org/10.1177/0049124189018002004

Malti, T., Ribeaud, D., \& Eisner, M. P. (2011). The Effectiveness of Two Universal Preventive Interventions in Reducing Children's Externalizing Behavior: A Cluster Randomized Controlled Trial. Journal of Clinical Child \& Adolescent Psychology, 40, 677 
692. https://doi.org/10.1080/15374416.2011.597084

Mash, E. J., \& Johnston, C. (1983). Parental Perceptions of Child Behavior Problems, Parenting Self-Esteem, and Mothers' Reported Stress in Younger and Older Hyperactive and Normal Children. Journal of Consulting and Clinical Psychology, 51, 86-99. https://doi.org/10.1037/0022-006X.51.1.86

Morgan, J., Robinson, D., \& Aldridge, J. (2002). Parenting Stress and Externalizing Child Behaviour. Child \& Family Social Work, 7, 219-225. https://doi.org/10.1046/j.1365-2206.2002.00242.x

Östberg, M., \& Hagekull, B. (2000). A Structural Modeling Approach to the Understanding of Parenting Stress. Journal of Clinical Child Psychology, 29, 615-625. https://doi.org/10.1207/S15374424JCCP2904_13

Östberg, M., \& Hagekull, B. (2013). Parenting Stress and External Stressors as Predictors of Maternal Ratings of Child Adjustment. Scandinavian Journal of Psychology, 54, 213-221. https://doi.org/10.1111/sjop.12045

Popkin, M. H. (2014). Active Parenting: 30 Years of Video-Based Parent Education. The Journal of Individual Psychology, 70, 166-175. https://doi.org/10.1353/jip.2014.0014

Prado, G., Cordova, D., Huang, S., Estrada, Y., Rosen, A., Bacio, G. A. et al. (2012). The Efficacy of Familias Unidas on Drug and Alcohol Outcomes for Hispanic Delinquent Youth: Main Effects and Interaction Effects by Parental Stress and Social Support. Drug and Alcohol Dependence, 125, S18-S25. https://doi.org/10.1016/j.drugalcdep.2012.06.011

Pratt, J. W. (1987). Dividing the Indivisible: Using Simple Symmetry to Partition Variance Explained. Paper presented at the Proceedings of the 2nd International Conference in Statistics, Tampere, Finland.

Prinzie, P., Deković, M., van den Akker, A. L., de Haan, A. D., Stoltz, S. E. M. J., \& Jolijn Hendriks, A. A. (2012). Fathers' Personality and Its Interaction with Children's Personality as Predictors of Perceived Parenting Behavior Six Years Later. Personality and Individual Differences, 52, 183-189.

Sanders, M. R., Ralph, A., Sofronoff, K., Gardiner, P., Thompson, R., Dwyer, S., \& Bidwell, K. (2008). Every Family: A Population Approach to Reducing Behavioral and Emotional Problems in Children Making the Transition to School. The Journal of Primary Prevention, 29, 197-222. https://doi.org/10.1007/s10935-008-0139-7

Schill, A. (2013). http://www.family-lab.se/

Schor, E. L., Billingsley, M. M., Golden, A. L., McMillan, J. A., Meloy, L. D., \& Pendarvis Jr., B. C. (2003). Family Pediatrics Report of the Task Force on the Family. Pediatrics, 111, 1541-1571.

SPAR (2010). Statens personadressregister (2013 ed.). Skatteverket. https://www.statenspersonadressregister.se/

Thorell, L. B. (2009). The Community Parent Education Program (COPE): Treatment Effects in a Clinical and a Community-Based Sample. Clinical Child Psychology and Psychiatry, 14, 373-387. https://doi.org/10.1177/1359104509104047

Ulfsdotter, M., Enebrink, P., \& Lindberg, L. (2014). Effectiveness of a Universal HealthPromoting Parenting Program: A Randomized Waitlist-Controlled Trial of All Children in Focus. BMC Public Health, 14, 1083. https://doi.org/10.1186/1471-2458-14-1083

Zhu, P., Sun, M.-S., Hao, J.-H., Chen, Y.-J., Jiang, X.-M., Tao, R.-X., Huang, K. and Tao, F.-B. (2014). Does Prenatal Maternal Stress Impair Cognitive Development and Alter Temperament Characteristics in Toddlers with Healthy Birth Outcomes? Develop mental Medicine \& Child Neurology, 56, 283-289. https://doi.org/10.1111/dmcn.12378 
Zubrick, S. R., Ward, K. A., Silburn, S. R., Lawrence, D., Williams, A. A., Blair, E. et al. (2005). Prevention of Child Behavior Problems through Universal Implementation of a Group Behavioral Family Intervention. Prevention Science, 6, 287-304.

https://doi.org/10.1007/s11121-005-0013-2

Submit or recommend next manuscript to SCIRP and we will provide best service for you:

Accepting pre-submission inquiries through Email, Facebook, LinkedIn, Twitter, etc. A wide selection of journals (inclusive of 9 subjects, more than 200 journals)

Providing 24-hour high-quality service

User-friendly online submission system

Fair and swift peer-review system

Efficient typesetting and proofreading procedure

Display of the result of downloads and visits, as well as the number of cited articles Maximum dissemination of your research work

Submit your manuscript at: http://papersubmission.scirp.org/

Or contact psych@scirp.org 